\title{
Relationship between volatile organic compounds released and growth of Cunninghamia lanceolata roots under low-phosphorus conditions
}

\author{
Huayan Lai, \\ Kai Wu, \\ Nemin Wang, \\ Wenjing Wu, \\ Xianhua Zou, \\ Xiangqing Ma, \\ Pengfei Wu
}

\begin{abstract}
To understand whether Chinese fir (Cunninghamia lanceolata) can conserve energy by reducing root volatiles to maintain growth under low phosphorus (P) conditions, we cultivated two half-sib families of Chinese fir that display high and low $P$ use efficiency under conditions of normal $P$ supply and total $P$ deficiency. Gas chromatography-mass spectrometry analysis was used to determine the content of root volatiles, and the relationships among root volatiles and root growth index, $\mathrm{P}$ content, and distribution were analyzed. There were significantly fewer volatile organic compounds (VOCs) in the rhizosphere of these two fir families, No. 25 and No. 32, under $P$ deficiency. Low $P$ supply significantly promoted root growth in No. 25 , increasing both average diameter and volume. A negative correlation was found between the volatiles and the increment of root average diameter and surface area. The belowground $P$ distribution and the root to shoot $\mathrm{P}$ concentration (Pr/Ps) were higher in No. 25 than in No. 32. The total amount of VOCs, as well as the amount of 18 individual volatiles were positively correlated with $P$ accumulation, aboveground $P$ distribution, and belowground $\mathrm{P}$ distribution, but the opposite pattern was seen in Pr/Ps for family No. 25 seedlings. We conclude that the content and types of VOCs differ among the Chinese fir genotypes. Under low-P stress, the roots of Chinese fir reduce the release of VOCs to maintain seedling growth.
\end{abstract}

Keywords: Cunninghamia lanceolata, Low-phosphorus Stress, Root Growth, Root Volatile Organic Compounds, Energy Balance

tain such a balance, some plants dissolve root cortical cells into the cavity, reducing respiratory needs and saving energy, and shift the dissolved $P$ to meet the needs of other parts of the plant (Burton et al. 2013, Wu et al. 2018). In some crop species, the root cortical aerenchyma are formed in the old root tissue to lower the respiratory consumption and ensure the normal growth of young tissues (Fan et al. 2003). Moreover, some plants or some genotypes within the same plant species effectively improve water and nutrient acquisition instead of accelerating root proliferation, as the metabolic costs of expanding the root system in the soil are very high (Lynch 2014, Strock et al. 2018).

The release of volatile organic compounds (VOCs) produced by different plant organs (leaves, flowers, fruits, and roots)

College of Forestry, Fujian Agriculture and Forestry University, Fuzhou, 350002 (China)

@ Pengfei Wu (fjwupengfei@126.com)

Received: Mar 21, 2018 - Accepted: Aug 21, 2018

Citation: Lai H, Wu K, Wang N, Wu W, Zou X, Ma X, Wu P (2018). Relationship between volatile organic compounds released and growth of Cunninghamia lanceolata roots under low-phosphorus conditions. iForest 11: 713-720. - doi: 10.3832/ifor2797-011 [online 2018-1106]

Communicated by: Claudia Cocozza

represents a loss of energy in the plants, but is known to be the key mediator in biotic interactions of both the shoot and root systems (Dudareva et al. 2006, Frost et al. 2008, Falik et al. 2014, Peñuelas et al. 2014). However, when plants coexist with individuals of the same species, they increase the secondary metabolism of phenols and antioxidants and reduce primary metabolism, such as leaf and root formation, in order to enhance their resistance to environmental stresses while maintaining a balance between energy generation and investment (Burton et al. 2013). In a study of Rosmarinus officinalis planted in a group, the phenolic compounds in leaves increased significantly, but the metabolism of lipids and amino acids decreased (Ormeño et al. 2007). In another study, bitou bush (Chrysanthemoides monilifera ssp. rotundata) released VOCs to inhibit the root growth of a neighboring plant (Isolepis nodosa [Rott.] R. Br) and maintain its dominance (Ens et al. 2009). Thus, adjusting the energy balance strategy is important for maintaining plant growth and coping with environmental stress (Lynch \& Ho 2005).

In previous studies, Chinese fir (Cunninghamia lanceolata [Lamb.] Hook.), a unique fast-growing timber species in south China, has been reported to reduce its energy expenditure under low- $P$ stress by significantly decreasing the leaf net photosynthetic rate, transpiration rate, and stomatal conductance (Chen et al. 2016, Farooq et 
al. 2018). However, the elite genotypes with high $\mathrm{P}$ use efficiency had a greater ability to forage available $P$ patches, dis playing increased root proliferation in the form of larger root surface area and root volume in P-poor than in P-rich patches (Wu et al. 2011, Zou et al. 2015). How can this energy-consuming behavior be reconciled with the need to reduce energy expenditure under $\mathrm{P}$ deficiency? As VOCs are an important secondary metabolite, we hypothesize that: (1) under low P stress, Chinese fir decreases the release of VOCs in order to reduce energy expenditure, to different extents in different genotypes; and (2) the content of VOCs released is negatively correlated with plant growth traits, especially with root morphological traits.

In the present study, conducted in two Chinese fir half-sib families with different $P$ use efficiencies, we measured the root growth increment, the average increase in root diameter, the root surface area increment, $\mathrm{P}$ accumulation, the $\mathrm{P}$ distribution pattern, and the release of VOCs from the rhizosphere of Chinese fir seedlings. The aim was to gain a better understanding of the energy metabolic balance associated with $P$ acquisition in Chinese fir by studying the regulatory mechanism under low- $P$ stress.

\section{Materials and methods}

\section{Plant materials}

Two half-sib Chinese fir families, No. 32 and No. 25, were selected from 1.5 generations of seed orchard at the state-owned forest farm in Zhangping, Fujian Province, SE China. These families were selected based on preliminary observations of significant differences $(p<0.05)$ in $P$ utiliza-

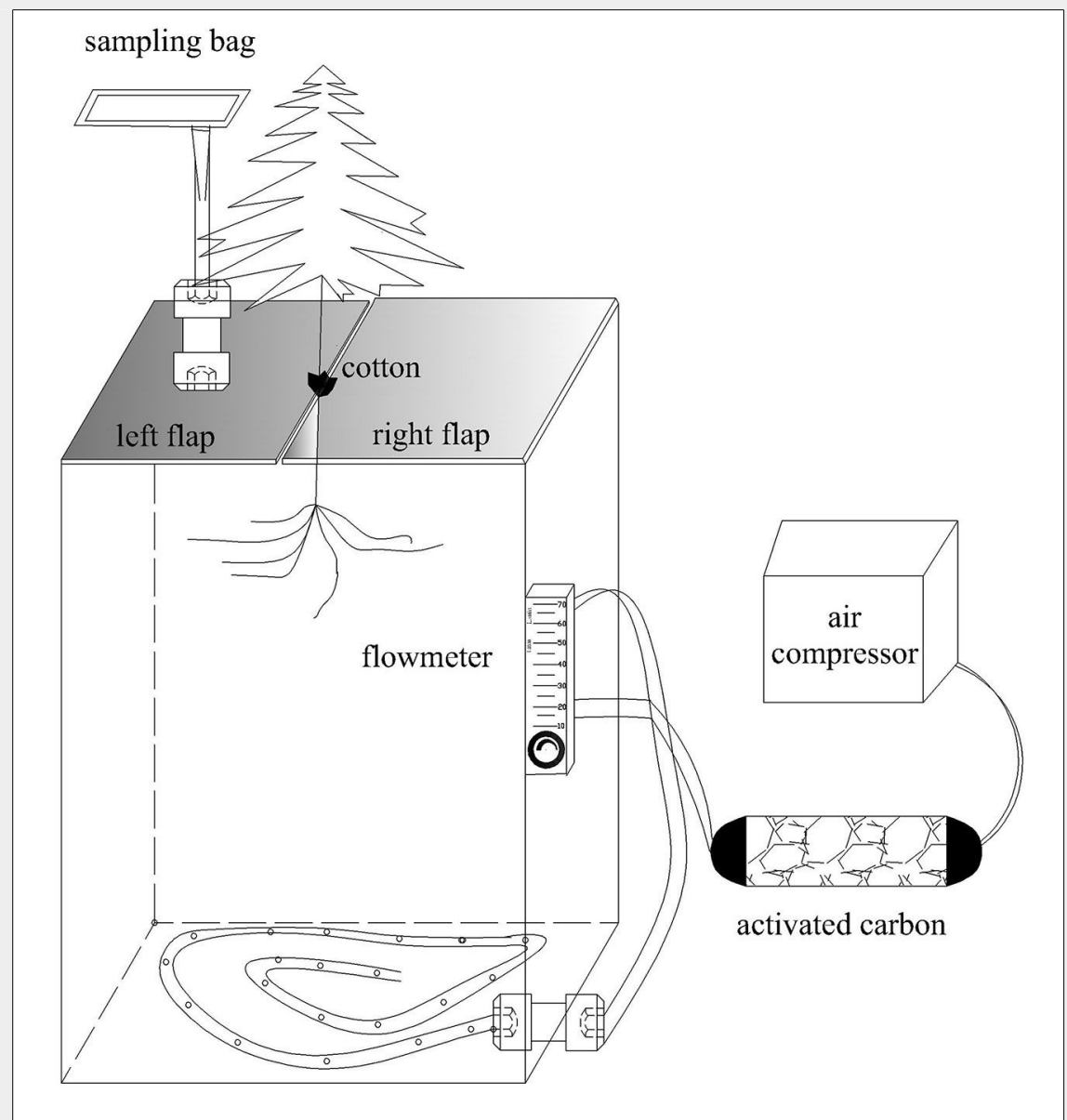

Fig. 1 - Schematic presentation of the collection of gases from the roots of Chinese fir seedlings. The collection device was made of polyvinyl fluoride (PVF), which is chemically inert. The PVF sampling bag can store the gas over a long period of time with no change to the concentration. The test device was a square box with a top divided into two flaps, the left side leading to an air outlet that was connected to the collection bag outside the tube. On the right side, an open air inlet was fixed to an annular hose, with a uniform hole to ensure uniform flow of gas. A gas flow meter was connected to the air inlet, providing a flow of air through activated carbon cylinders to clean the air. VOCs released by the roots at the bottom of the tube flowed up to the air outlet. The sides of the tube, the bottom plate, and the top cover were $5 \mathrm{~mm}$ thick and made of acrylic material; the square pipe joints were watertight, and the entire test device was airtight when closed. To ensure that no air leaked out of the box, tape was used to seal the top flaps. tion efficiency, with No. 32 showing lower efficiency than No. 25 under no-P conditions. For this preliminary experiment, sixmonth-old seedlings were planted in pots and harvested three months after the start of the treatments (Wu et al. 2018). Hence, we used healthy, six-month-old, uniform seedlings ( $14.02 \pm 0.42 \mathrm{~cm}$ in height, $2.48 \pm$ $0.10 \mathrm{~mm}$ in root collar diameter) from the forest farm as the test subjects. They were cultivated in washed sand containing available $\mathrm{P}$ at $0.034 \pm 0.007 \mathrm{mg} \mathrm{kg}^{-1}$.

\section{Experimental design}

Each seedling was cultivated in ad-hoc designed acrylic pots, which were $15 \mathrm{~cm}$ long, $15 \mathrm{~cm}$ wide, and $20 \mathrm{~cm}$ in height (Fig. 1) in the greenhouse at the College of Forestry, Fujian Agriculture and Forestry University, starting on October 30, 2016. Temperature in the greenhouse ranged from $18^{\circ} \mathrm{C}$ to 28 ${ }^{\circ} \mathrm{C}$, and the relative humidity was $65.2 \%$ and $78.7 \%$ during the light and dark periods of the experiment, respectively. To each pot we added $4.5 \mathrm{~kg}$ of cleaned sand passed through a 2-mm sieve and $10 \mathrm{~g}$ crystal mud (Shenyang base stone, Shuanglong Chemical Co., China) that absorbed the Hoagland solution (Wu et al. 2011) for $24 \mathrm{~h}(1 \mathrm{~g}$ dry crystal mud, with a particle size of $1 \mathrm{~mm}$, can absorb $100 \mathrm{~mL}$ solution).

The seedlings from two families were assigned to one of two $\mathrm{P}$ levels, normal $\mathrm{P}\left(\mathrm{P}_{1}\right.$ : $\left.1.0 \mathrm{mmol} \mathrm{L}^{-1} \mathrm{KH}_{2} \mathrm{PO}_{4}\right)$ and no $\mathrm{P}\left(\mathrm{P}_{0}\right.$ : $0 \mathrm{mmol}$ $\left.\mathrm{L}^{-1} \mathrm{KH}_{2} \mathrm{PO}_{4}\right)$. Each treatment was replicated five times. A 200-mL volume of deionized water was poured into the pot once every 2 days (at 7:00 p.m.), with water potential 70\% (moisture probe mp-406, ICT International Pty, Armidale, NSW, Australia).

\section{Data collection}

\section{VOC collection and detection}

The rhizosphere VOCs were collected at 10:00 a.m. on day 7, 14, and 21 during the experiment. VOCs were collected three times from three replicates, as well as from two control containers that contained different $P$ levels but no seedlings. The VOCs released in the pots were collected by dynamic headspace collection (Robert et al. 2012) as follows (Fig. 1). First, the left and right top flaps were closed. To fill any gaps between the planting trough and the stem of the seedling, a layer of cotton was wrapped around the stem of the seedling. Secondly, a 2-L volume of PVF (polyvinyl fluoride) sampling bag (model TD-4501, Dalian Deling Gas Packaging Co., Liaoning, China) was pumped to vacuum standby. A drum-type collection device was used with an air compressor to force the air through the activated carbon, pass the gas flow meter, through the sealed rhizosphere containing plants, and into the collection bag. Next, the air compressor was opened and the gas flow meter was adjusted to $20 \mathrm{~L}$ $\mathrm{min}^{-1}$, the system was ventilated for 2 minutes to drain the air from the unit, and the collection bag switch was opened. Finally, 
Fig. 2 - The amounts and types of 18 volatile organic compounds (VOCs) released from Chinese fir roots after 21 days of lowphosphorus stress. Within each panel, bars (means \pm

SE) labeles by the same lowercase letter are not significantly different $(p>0.05)$
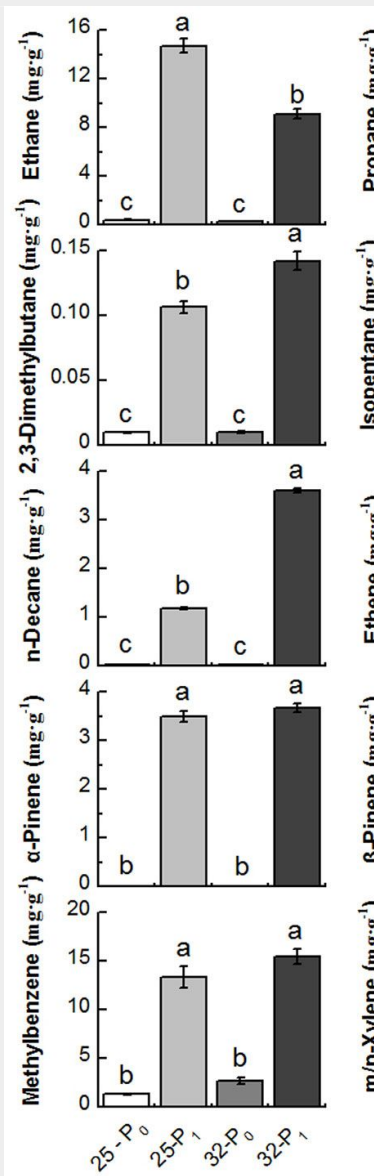
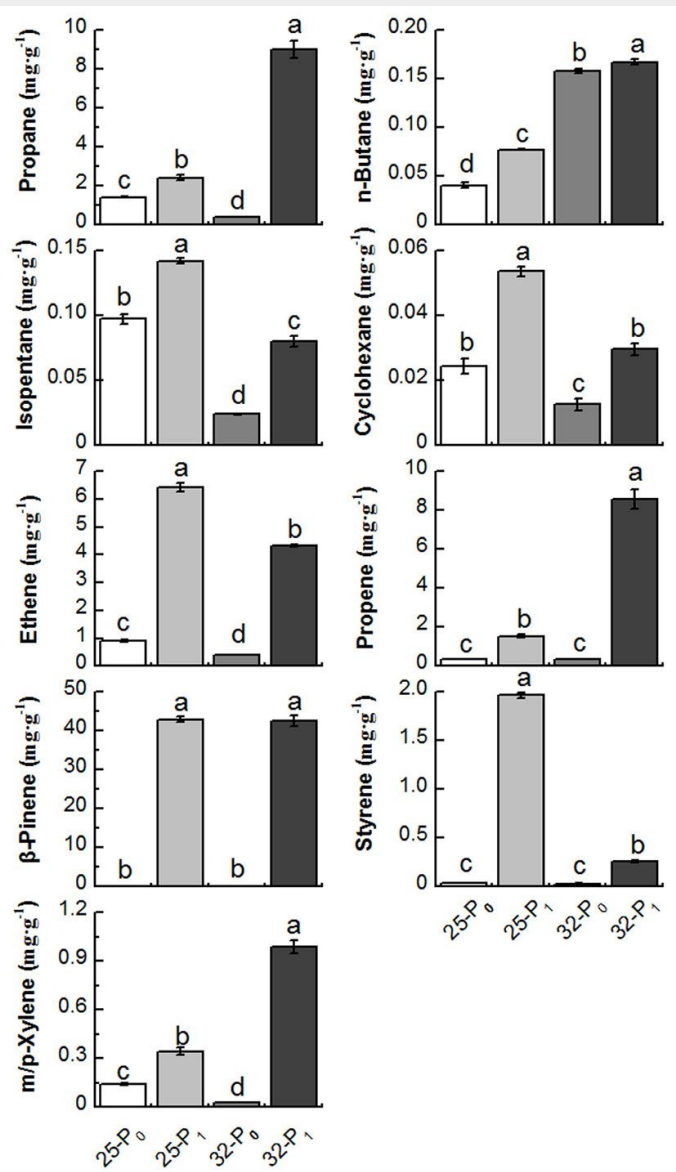

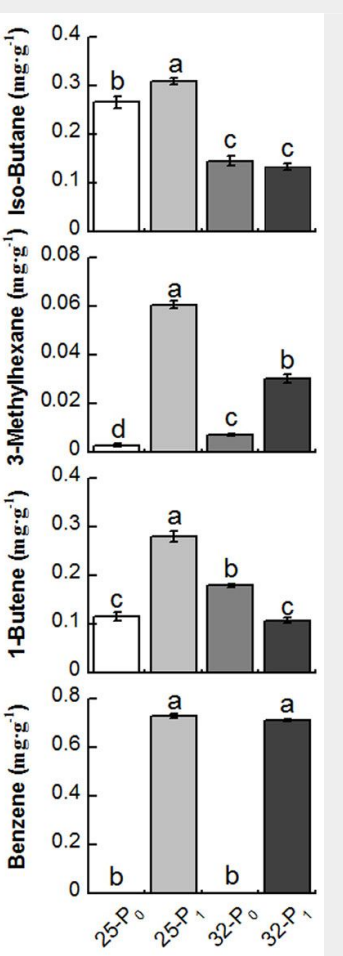

the collection bag switch and the air compressor switch were closed while the bag was filled. After collection, the sampling bag was wrapped in a black opaque plastic bag to prevent the VOCs from decomposing.

Roots can produce a large amount of VOCs such as terpenes (Lin et al. 2007). In the present study, 18 VOCs (Fig. 2) were screened and tested (Peñuelas et al. 2014). The VOCs were analyzed by gas chromatography-mass spectrometry (GC-MS$\mathrm{QP7890B}^{\circledast}$, Agilent Technologies, Santa Clara, CA, USA) operating in EI mode at 70 ev, with a source temperature of $230^{\circ} \mathrm{C}$, scanning range $35-350 \mathrm{amu}$, and sweeping speed at $3.125 \mathrm{u} \mathrm{s}^{-1}$. The GC-MS was fitted with a fused silica HP1 capillary column (60 $\mathrm{m} \times 0.32 \mathrm{~mm}$ ) with helium as the carrier gas

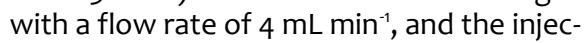
tor temperature was set at $200{ }^{\circ} \mathrm{C}$ in splitless mode. The oven temperature program started at $10{ }^{\circ} \mathrm{C}$ and remained at that temperature for $3 \mathrm{~min}$, increased by $5{ }^{\circ} \mathrm{C} \mathrm{min}^{-1}$ until it reached $120^{\circ} \mathrm{C}$, then increased by 10 ${ }^{\circ} \mathrm{C} \mathrm{min}-1$ to $250^{\circ} \mathrm{C}$ and remained at $250^{\circ} \mathrm{C}$ for 7 min, with a 3 -min scan. The compounds were identified by comparison with mass spectra in NIST 14.

\section{Root morphology traits and P distribution determination}

The tested seedlings were harvested on November 20, 2016 (21 days after the treatments were initiated). All roots were care- fully cleaned with distilled water and dried with filter paper, and the root system image was scanned. Then the root morphological traits such as root length, surface area, total volume, and average diameter were analyzed using WinRHIZO ${ }^{\mathrm{TM}}$ ver. $4.0 \mathrm{~B}$ root analysis system software (Regent Instruments Inc., Sainte-foy, Quebec, Canada), after scanning by a Canadian Digital Scanner (STD1600 ${ }^{\oplus}$, Epson, USA). The increments in root morphological traits were calculated as differences in each trait before and after the treatments.

The harvested seedlings were divided

into aboveground and belowground parts, oven dried at $105{ }^{\circ} \mathrm{C}$ for $30 \mathrm{~min}$ to deactivate enzymes, and then dried at $79{ }^{\circ} \mathrm{C}$ to constant mass to determine dry mass and $P$ concentration. The aboveground and belowground parts of the seedlings were crushed, after which $0.2 \mathrm{~g}$ of the air-dried sample was passed through a 2-mm sieve and weighed. The crushed samples were digested with $\mathrm{H}_{2} \mathrm{SO}_{4}-\mathrm{HClO}_{4}$. The $\mathrm{P}$ concentrations of the seedlings were measured by phosphomolybdate following the method described in He et al. (2003). We calculated aboveground $\mathrm{P}$ distribution by multiplying

Tab. 1 - Effects of Chinese fir family and phosphorus (P) supply level on root morphological traits, $P$ allocation patterns and amount of volatile organic compounds (VOCs) released by roots of seedlings. F-values are given with their level of significance. $\left(^{*}\right)$ : $p<0.05 ;(* *): p<0.01$.

\begin{tabular}{|c|c|c|c|c|}
\hline \multirow{2}{*}{\multicolumn{2}{|c|}{ Group/Variable }} & \multicolumn{3}{|c|}{ Factors ( $F$-values) } \\
\hline & & \multirow{2}{*}{$\begin{array}{c}\begin{array}{c}\text { Family } \\
\text { (F) }\end{array} \\
7.40^{*}\end{array}$} & \multirow{2}{*}{$\begin{array}{c}\begin{array}{c}\text { P supply } \\
\text { level (P) }\end{array} \\
34.48^{* *}\end{array}$} & \multirow{2}{*}{$\begin{array}{l}\mathrm{F} \times \mathrm{P} \\
9.32^{*}\end{array}$} \\
\hline Amount of $\mathrm{VO}$ & & & & \\
\hline \multirow{4}{*}{$\begin{array}{l}\text { Increment of } \\
\text { root } \\
\text { morphology } \\
\text { traits }\end{array}$} & Root length & $68.22^{* *}$ & 0.37 & 1.47 \\
\hline & Root surface area & $42.33^{* *}$ & 4.39 & 0.41 \\
\hline & Root average diameter & $18.33^{* *}$ & $13.43^{*}$ & $5.63^{*}$ \\
\hline & Root volume & $90.30^{* *}$ & $62.23^{* *}$ & $34.82^{* *}$ \\
\hline \multirow{4}{*}{$\begin{array}{l}\text { P allocation } \\
\text { patterns }\end{array}$} & $P$ accumulation of whole plant & 3.32 & $14.97^{*}$ & 0.005 \\
\hline & $\mathrm{P}$ accumulation of root & 1.46 & $15.11^{* *}$ & 0.007 \\
\hline & $\mathrm{P}$ accumulation of shoot & $6.56^{*}$ & 0.52 & 0.001 \\
\hline & $\mathrm{Pr} / \mathrm{Ps}$ & $7.77^{*}$ & 3.19 & 1.32 \\
\hline
\end{tabular}




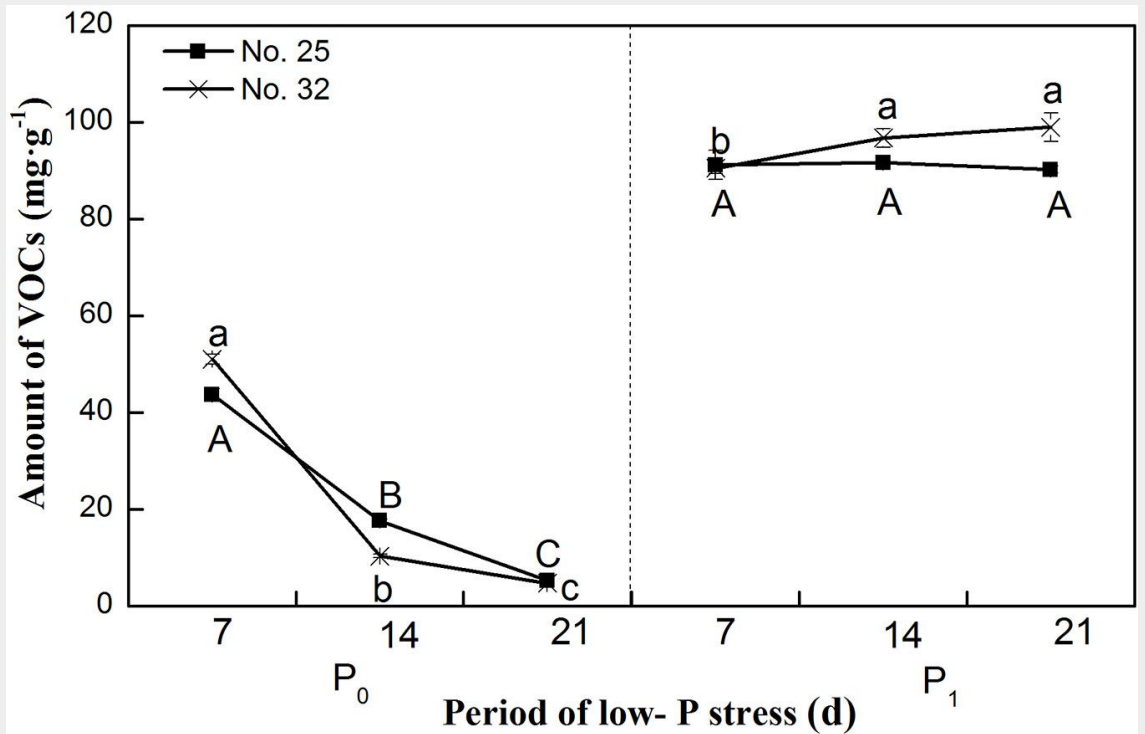

Fig. 3 - Changes in the amounts of volatile organic compounds (VOCs) released by Chi nese fir seedlings under different phosphorus supply conditions for different periods of time. Within each inflection point, bars (means \pm SE) labeled by the same lowercase letter are not significantly different ( $p>0.05)$ in family no. 32 seedlings, by the same capital letter are not significantly different $(p>0.05)$ in family no. 25 seedlings.

aboveground $\mathrm{P}$ concentration by above- Data analysis ground dry biomass, and belowground $P$ distribution following a similar process. The total $P$ accumulation equaled aboveground $\mathrm{P}$ distribution plus belowground $\mathrm{P}$ distribution. To estimate the $P$ translocation efficiency, we calculated root to shoot $\mathrm{P}$ concentration ratio (Pr/Ps).
$\left(\mathrm{P}_{\mathrm{o}}\right.$ and $\mathrm{P}_{1}$ ) on the amount of VOCs released by Chinese fir roots, using the software package SPSS ${ }^{\circledast}$ ver. 19.0 (IBM, Armonk, NY, USA). In addition, the differences in growth, distribution of $\mathrm{P}, \mathrm{P}$ accumulation per family, $P$ supply, and the interaction of these factors were examined. Means that exhibited significant differences $(p<0.05)$ were examined by LSD multiple comparison method. Correlations between growth traits and $\mathrm{P}$ accumulation and between $\mathrm{P}$ distribution and VOC content at different $P$ treatments were also analyzed, and differences were considered significant at the 0.05 level and highly significant at the 0.01 level (2-tailed). All data were expressed as mean \pm standard error

\section{Results}

\section{VOC types and amounts released by} roots of Chinese fir under $P$ stress

There was significant two-way interaction effects between Chinese fir family and $P$ supply level on the amounts of VOCs released by roots, and both factors significantly affected the VOCs amounts on an individual basis $(p<0.05-$ Tab. 1$)$.

The amount of VOCs released by both Chinese fir families was lower under $\mathrm{P}$ deficiency $\left(\mathrm{P}_{\mathrm{o}}\right)$ treatment than under normal $\mathrm{P}$ supply (Fig. 3). As the duration of the experiment continued, the amount of VOCs decreased strongly and the difference in amount of VOCs reached a significant level under $\mathrm{P}$ deficient treatment, whereas the amount did not change significantly under
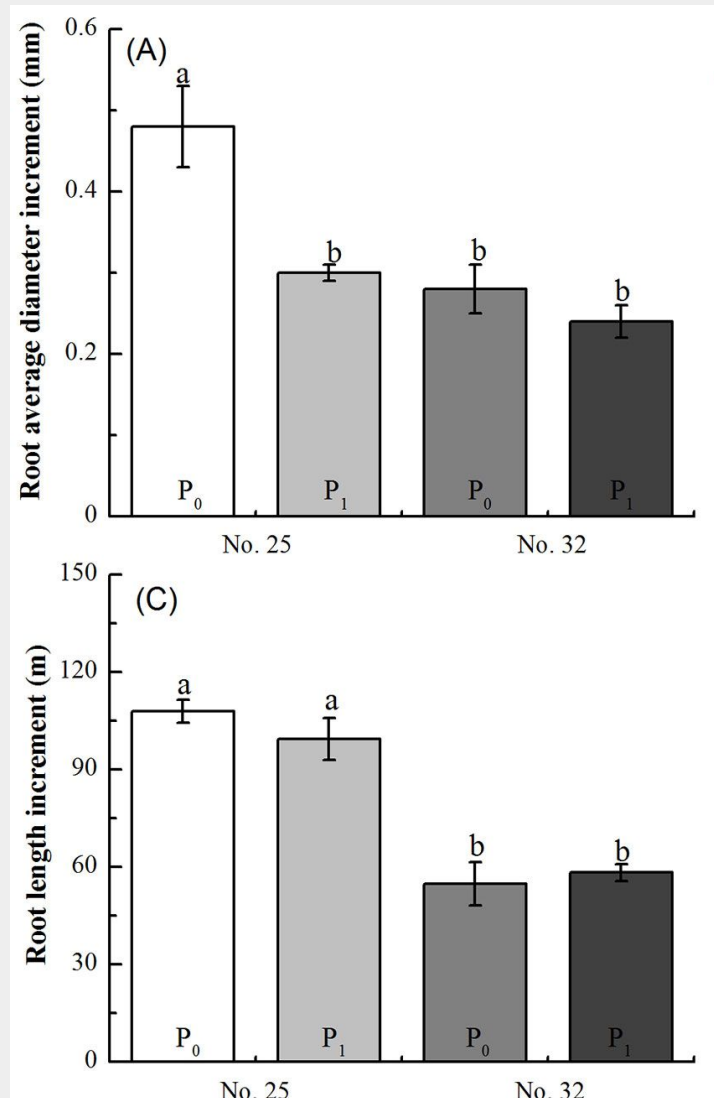
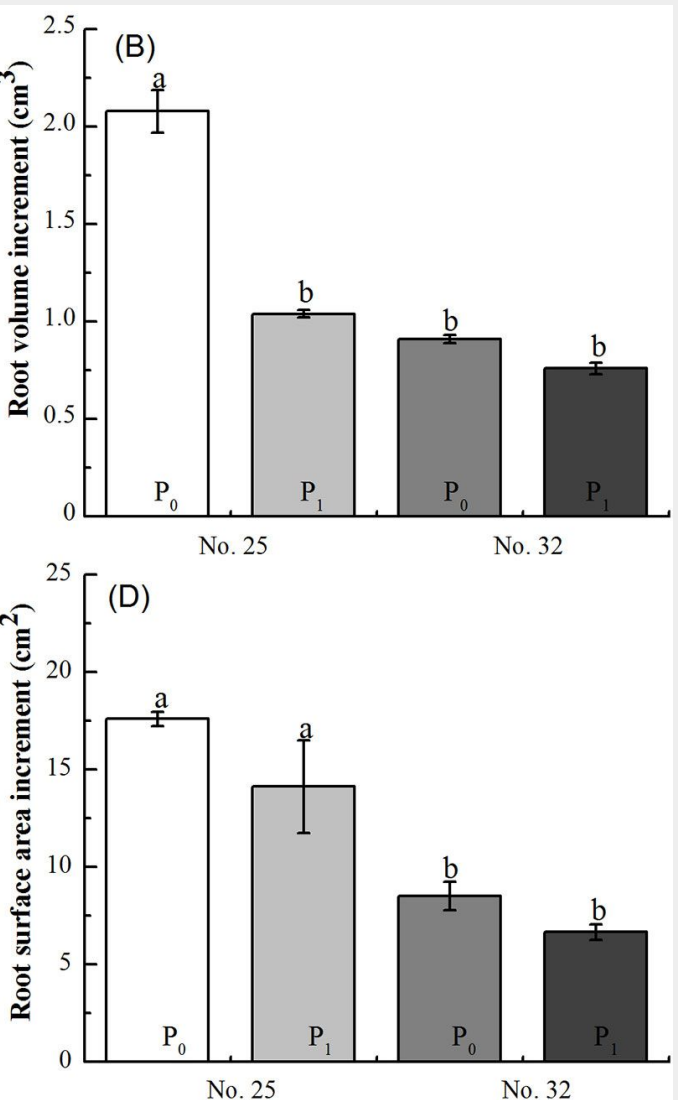

Fig. 4 - Difference in the root length increment $(A)$, average root diameter increment (B), root surface area increment (C), and root volume increment $(D)$ between two genotypes of Chinese fir seedlings (families no. 25 and no. 32) under low-phosphorus stress. Within each panel, bars (means \pm SE) labeled with the same lowercase letter are not significantly different ( $p>0.05)$. 
normal $\mathrm{P}$ supply treatment. Interestingly, $\mathrm{P}$ deficiency promoted the release of 1-butene from family No. 32 seedling root at 21 days, while the amounts of other types of VOCs released from both two families were significantly less under $P$ deficient than under normal P supply treatment (Fig. 2), similar pattern at 7 days and 14 days was observed (see Fig. S1 and Fig. S2 in Supplementary material for the original data used to perform this analysis).

\section{Relationship between root growth and} amount of VOCs under $P$ stress

\section{Root growth}

There was significant two-way interaction effects between Chinese fir family and $P$ supply level on the increments of root average diameter and volume $(p<0.05)$, but not on the increments of root length and surface area $(p>0.05-$ Tab. 1). Low $P$ stress significantly promoted growth of average root diameter (Fig. 4A) and root volume (Fig. 4B) in family No. 25 seedlings compared with the family No. 32 seedlings. As individual factors, $P$ supply level non-significantly affected either root length or surface area $(p>0.05)$. In contrast, the root morphology growth was significantly different in the two families $(p<0.05-$ Tab. $1)$; both the increments of root length and surface area of family No. 25 seedling roots were larger than those of family No. 32 (Fig. 4C, Fig. 4D).

\section{Correlation between root growth and amount of VOCs}

For family No. 25 seedlings, the correlation between the amount of 18 individual VOCs and the increment of root average diameter was not significant $(p>0.05)$, but the increment of root volume was negatively correlated with the total amount of VOCs or the 18 individual VOCs $(p<0.05-$ Tab. 2). For family No. 32 seedlings, there was a negative correlation between the amount of 16 individual VOCs and the increment of root average diameter, while the increment of root volume was positively correlated, the relationship with the release of 1-butene was inverse; however, neither of these measures reached a significant level ( $p>0.05-$ Tab. 2$)$.

Relation between $P$ accumulation/allocation and VOC amount under $P$ stress

\section{$P$ accumulation and allocation}

The effect of Chinese fir family on $\mathrm{P}$ accumulation of root system was significant ( $p$ $<0.05$ - Tab. 1). The P supply level had a significant effect both on $P$ accumulation of the whole plant and the shoot $(p<0.05$ - Tab. 1). Compared to $P$ deficient treatment, the $\mathrm{P}$ accumulation of the whole plant and the shoot of families No. 25 and No. 32 were significantly lower than that of normal $P$ supply treatment $(p<0.05-$ Fig. 5A, Fig. 5B), but not in $\mathrm{P}$ accumulation of root system ( $p<0.05-$ Fig. $5 C)$. Moreover,
Tab. 2 - Relationship between root morphology traits and amount of volatile organic compounds (VOCs) released by roots of Chinese fir seedlings. (AD): Average diameter increment; (V): Volume increment; (L): Length increment; (SA): Surface area increment; (*): $p<0.05$ (2-tailed); (**): $p<0.01$ (2-tailed).

\begin{tabular}{lllllllll}
\hline \multirow{2}{*}{ VoC } & \multicolumn{9}{c}{ Family no. 25 } & \multicolumn{7}{c}{ Family no. 32 } \\
\cline { 2 - 8 } & AD & $\mathbf{V}$ & $\mathbf{L}$ & $\mathrm{SA}$ & $\mathrm{AD}$ & $\mathbf{V}$ & $\mathrm{L}$ & $\mathrm{SA}$ \\
\hline Total VOCs & -0.79 & $-0.94^{*}$ & -0.65 & -0.24 & -0.58 & 0.06 & 0.02 & -0.62 \\
\hline Ethane & -0.8 & $-0.93^{* *}$ & -0.68 & -0.17 & -0.56 & 0.05 & 0.02 & -0.6 \\
\hline Propane & -0.76 & $-0.90^{*}$ & -0.62 & -0.24 & -0.56 & 0.05 & 0.02 & -0.6 \\
\hline n-Butane & -0.72 & $-0.96^{* *}$ & -0.71 & -0.26 & -0.41 & 0.13 & 0.04 & -0.11 \\
\hline Iso-butane & -0.59 & $-0.84^{*}$ & $-0.90^{*}$ & 0.002 & 0.65 & 0.51 & 0.7 & 0.78 \\
\hline 2,3-Dimethylbutane & -0.79 & $-0.93^{* *}$ & -0.65 & -0.24 & -0.53 & 0.08 & 0.02 & -0.6 \\
\hline Isopentane & -0.66 & $-0.98^{* *}$ & -0.67 & -0.3 & -0.54 & 0.12 & 0.04 & -0.71 \\
\hline Cyclohexane & -0.74 & $-0.94^{* *}$ & -0.7 & -0.3 & -0.49 & 0.04 & 0.08 & $-0.82^{*}$ \\
\hline 3-Methylhexane & -0.8 & $-0.94^{* *}$ & -0.68 & -0.19 & -0.5 & 0.08 & 0.01 & -0.57 \\
\hline n-Decane & -0.79 & $-0.94^{* *}$ & -0.66 & -0.22 & -0.58 & 0.08 & 0.01 & -0.64 \\
\hline Ethene & -0.79 & $-0.94^{* *}$ & -0.66 & -0.21 & -0.58 & 0.08 & 0.02 & -0.63 \\
\hline Propene & -0.75 & $-0.94^{* *}$ & -0.59 & -0.35 & -0.51 & 0.1 & 0.03 & -0.63 \\
\hline 1-Butene & -0.71 & $-0.96^{* *}$ & -0.58 & -0.35 & 0.56 & -0.22 & 0.08 & 0.67 \\
\hline a-Pinene & -0.8 & $-0.94^{* *}$ & -0.67 & -0.19 & -0.57 & 0.07 & 0.02 & -0.62 \\
\hline B-Pinene & -0.79 & $-0.94^{* *}$ & -0.65 & -0.23 & -0.59 & 0.06 & 0.01 & -0.62 \\
\hline Styrene & -0.8 & $-0.94^{* *}$ & -0.66 & -0.21 & -0.61 & 0.09 & -0.02 & -0.65 \\
\hline Benzene & -0.79 & $-0.94^{* *}$ & -0.65 & -0.22 & -0.58 & 0.08 & 0.02 & -0.64 \\
\hline Methylbenzene & -0.76 & $-0.93^{* *}$ & -0.57 & -0.36 & -0.6 & 0.02 & 0.01 & -0.63 \\
\hline m/p-Xylene & -0.77 & $-0.91^{*}$ & -0.52 & -0.32 & -0.56 & 0.11 & 0.02 & -0.67 \\
\hline
\end{tabular}

the $\mathrm{P}$ accumulation in the roots and the $\mathrm{Pr} / \mathrm{Ps}$ were higher for family No. 25 than for family No. 32 seedlings ( $p<0.05-$ Fig. $5 C$, Fig. 5D).

\section{Correlation between $\mathrm{P}$ accumulation and allocation with amount of VOCs}

The total amount of VOCs and the 18 individual VOCs were positively correlated with

$\mathrm{P}$ accumulation in the whole plant, shoots, and root system, but the opposite pattern was seen in $\mathrm{Pr} / \mathrm{Ps}$ for family No. 25 Chinese fir seedlings (Tab. 3). Moreover, for family No. 25 seedlings, there was a significant correlation between $\mathrm{P}$ accumulation in the whole plant and the 18 types of volatiles except 1-butene $(p<0.05)$. For family No. 32 , the correlation between the individual

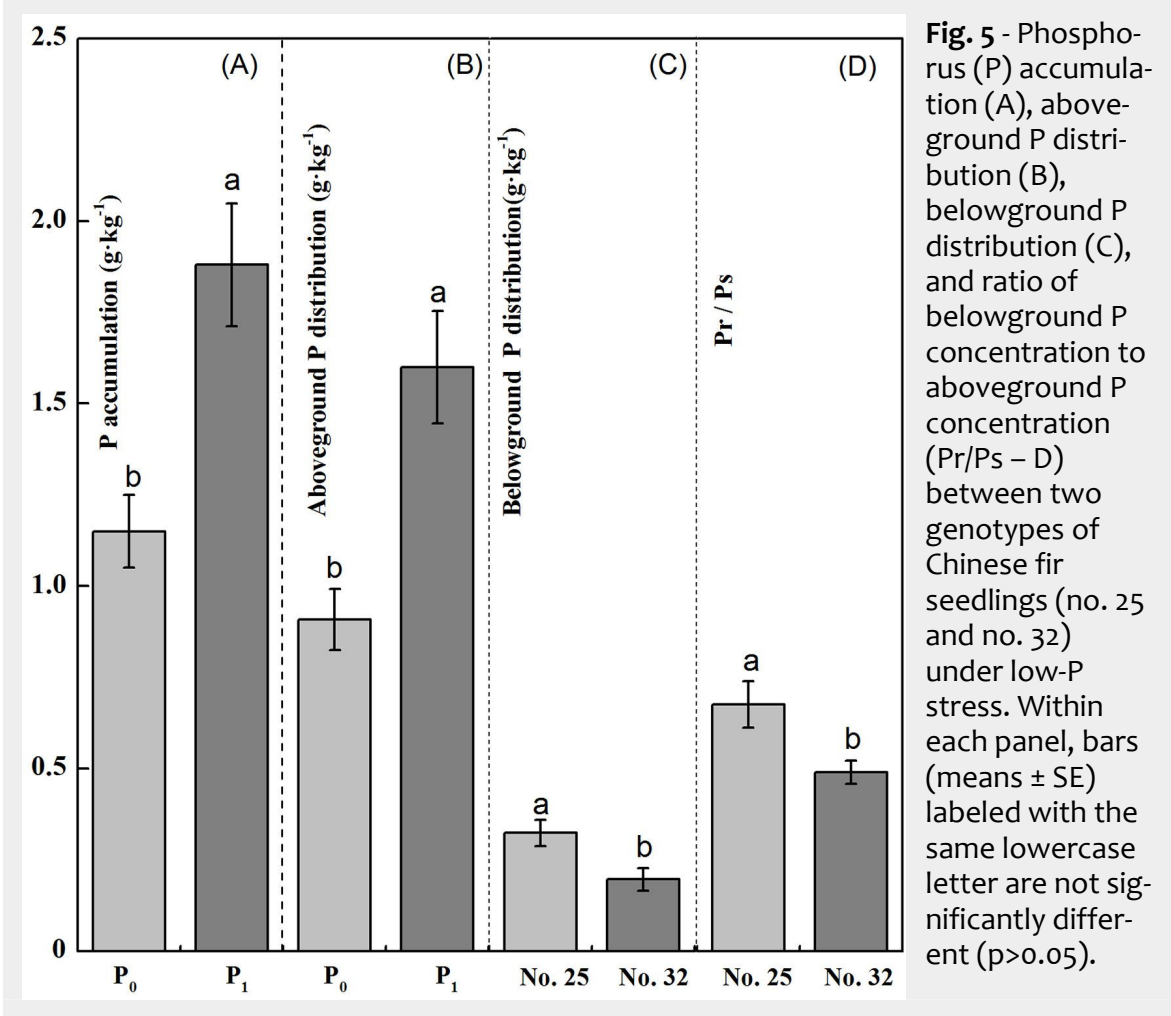


Tab. 3 - Relationship between phosphorus allocation traits and amount of volatile organic compounds (VOCs) released by roots of Chinese fir seedlings. (PAW): P accumulation in whole plant; (APD): aboveground $\mathrm{P}$ distribution; (BPD): belowground $\mathrm{P}$ distribution; ( $\mathrm{Pr} / \mathrm{Ps}$ ): root-shoot $\mathrm{P}$ concentration ratio; $\left(^{*}\right): \mathrm{p}<0.05$ (2-tailed); $\left.{ }^{* *}\right): \mathrm{p}<$ 0.01 (2-tailed).

\begin{tabular}{lllllllll}
\hline \multirow{2}{*}{ voc } & \multicolumn{7}{l}{ Family no. 25 } & \multicolumn{7}{c}{ Family no. 32 } \\
\cline { 2 - 10 } & PAW & APD & BPD & Pr/Ps & PAW & APD & BPD & Pr/Ps \\
\hline Total VOCs & $0.88^{*}$ & 0.71 & 0.19 & -0.49 & 0.73 & $0.86^{*}$ & 0.09 & -0.76 \\
\hline Ethane & $0.91^{*}$ & 0.66 & 0.16 & -0.53 & 0.75 & $0.86^{*}$ & 0.06 & -0.76 \\
\hline Propane & $0.88^{*}$ & 0.8 & 0.35 & -0.46 & 0.74 & $0.87^{*}$ & 0.07 & -0.76 \\
\hline n-Butane & $0.86^{*}$ & 0.73 & 0.3 & -0.53 & 0.8 & 0.78 & -0.13 & -0.5 \\
\hline Iso-butane & $0.84^{*}$ & 0.59 & 0.5 & -0.59 & -0.39 & -0.19 & 0.2 & 0.09 \\
\hline 2,3-Dimethylbutane & $0.89^{*}$ & 0.68 & 0.15 & -0.48 & 0.76 & $0.84^{*}$ & 0.05 & -0.76 \\
\hline Isopentane & $0.83^{*}$ & 0.75 & 0.31 & -0.56 & 0.72 & 0.75 & 0.12 & -0.76 \\
\hline Cyclohexane & $0.84^{*}$ & 0.77 & 0.32 & -0.44 & 0.68 & 0.7 & 0.1 & -0.8 \\
\hline 3-Methylhexane & $0.90^{*}$ & 0.68 & 0.18 & -0.52 & 0.77 & $0.85^{*}$ & 0.03 & -0.76 \\
\hline n-Decane & $0.89^{*}$ & 0.7 & 0.18 & -0.51 & 0.72 & $0.84^{*}$ & 0.1 & -0.76 \\
\hline Ethene & $0.89^{*}$ & 0.68 & 0.19 & -0.52 & 0.73 & $0.85^{*}$ & 0.1 & -0.76 \\
\hline Propene & $0.82^{*}$ & 0.76 & 0.21 & -0.43 & 0.77 & 0.79 & 0.05 & -0.76 \\
\hline 1-Butene & 0.81 & 0.76 & 0.22 & -0.48 & -0.64 & -0.78 & -0.25 & 0.77 \\
\hline a-Pinene & $0.90^{*}$ & 0.67 & 0.16 & -0.52 & 0.73 & $0.85^{*}$ & 0.09 & -0.76 \\
\hline B-Pinene & $0.89^{*}$ & 0.7 & 0.18 & -0.5 & 0.72 & $0.87^{*}$ & 0.1 & -0.76 \\
\hline Styrene & $0.90^{*}$ & 0.7 & 0.18 & -0.51 & 0.67 & $0.86^{*}$ & 0.17 & -0.76 \\
\hline Benzene & $0.89^{*}$ & 0.7 & 0.18 & -0.5 & 0.72 & $0.84^{*}$ & 0.11 & -0.76 \\
\hline Methylbenzene & $0.83^{*}$ & $0.82^{*}$ & 0.28 & -0.41 & 0.69 & $0.90^{*}$ & 0.1 & -0.77 \\
\hline m/p-Xylene & $0.85^{*}$ & $0.82^{*}$ & 0.27 & -0.44 & 0.72 & 0.79 & 0.12 & -0.76 \\
\hline & & & & & & & & \\
\hline & & & & & & & 0.70 \\
\hline
\end{tabular}

amount of 16 types of VOCs and P accumulation in the whole plant was positive, while $\operatorname{Pr} / \operatorname{Ps}$ was positively correlated, the relationship with the release of either isobutane or 1-butene being inverse; however, neither of these $V O C s$ reached a significant level $(p>0.05-$ Tab. 2$)$.

\section{Discussion}

Different plant species produce different kinds of VOCs (Bruinsma et al. 2009), and there are also notable differences between genotypes (Dam et al. 2010). The present study showed that the VOCs released by two Chinese fir families were different. Significantly higher amounts of iso-butane, cyclohexane, and ethane were released from family No. 25 seedlings in response to different P levels compared with family No. 32 seedlings, although more n-butane was released by family No. 32 seedlings. Under $P$ deficiency, the total amounts of VOCs released by family No. 25 and 32 were lower than under normal $\mathrm{P}$ supply level (Fig. 3). With the increasing duration of $P$ deficiency, the amounts of VOCs released was severely inhibited, and the difference in the amount of VOCs reached a significant level under $\mathrm{P}$ deficient condition. Evidently, the seedlings responded to $P$ stress by reducing its secondary metabolism to conserve resources and shifting the limited remaining resources to more vital functions. More metabolic resources are required for tasks such as resource acquisition, growth, and reproduction (Lynch 1998, Strock et al. 2018). However, P deficiency promoted the release of 1-butene from family No. 32 seedling root system in this study (Fig. 3); similarly, emission of a type of VOC (isoprene) increased in Phragmites australis exposed to low $\mathrm{P}$ concentrations (Fares et al. 2008). They found that isoprene emission was limited by processes other than the availability of photosynthetic byproducts or by energetic (ATP) requirements under high P supply levels.

The nutrient use efficiency of plants depends on resource availability and utilization. Chiou \& Lin (2011) reported that plants possess a multivariate signal network consisting of hormones, sugars, miRNA, and other modulators that work at different levels of regulation. The two Chinese fir families analyzed in this study (No. 25 and No. 32) used different strategies to cope with low-P stress, which may be the reason for the difference in the release of VOCs from their roots. Family No. 25, similar to other Chinese fir genotypes, exhibited "active capture of soil P," and as such, mainly adapts to low-P conditions via strong root proliferation and exudation of chemical substances (Wu et al. 2011, Zou et al. 2015, 2018). In contrast, family No. 32 is like the "passive low-P tolerance" genotype and could produce a high yield when the available soil $\mathrm{P}$ concentration was lower than that required by the average genotype, which mainly resists low-P stress by accelerating the internal $\mathrm{P}$ cycle of the plant body, e.g., via improving the efficiency of $\mathrm{P}$ utilization by dissolving root cortex cells (Wu et al. 2018). In the present study, the root length and surface area of family No. 25 seedling were larger than those of family No. 32 (Fig. 4C, Fig. 4D). According to the principle of conservation of energy, genotypes with high $\mathrm{P}$ efficiency need to consume more energy (Fan et al. 2003) and to balance their energy metabolism by reducing the emission of root volatiles.

The metabolic cost of soil exploration is an important component of plant growth under low P availability (Lynch \& Ho 2005). The lack of soluble $P$ in the soil caused roots to expend more energy trying to detect $P$ resources (Lynch 2014). The VOCs released by roots represent a metabolic cost, so reducing the VOCs is an adaptation to save energy (Asensio et al. 2007). In the present study, VOCs produced by the root system of Chinese fir seedlings under $\mathrm{P}$ deficiency affected the $P$ accumulation of the whole plant, the distribution pattern of $P$ between the root and shoot portions of the seedlings, and root growth. As the duration of $\mathrm{P}$ stress was prolonged, significant differences developed in the amount of VOCs released by different families under different $P$ treatments. Many principles associated with resource allocation and acquisition are analogous to optimization theory in economics, especially with regard to limited internal resources and constrained availability of external resources (Lynch \& Ho 2005).

The genotype with high $\mathrm{P}$ use efficiency is well suited to economic analysis (Lynch \& Ho 2005). Under P deficiency, the belowground $\mathrm{P}$ distribution and $\mathrm{Pr} / \mathrm{Ps}$ of family No. 25 were higher than those of family No. 32. Increased relative allocation to root growth is obviously beneficial for $\mathrm{P}$ acquisition (Nielsen et al. 2001). The physiological responses to Chinese fir to no-P stress include altering the distribution and structure of roots (Wu et al. 2011), dissolution of root cortical cells (Burton et al. 2013, Wu et al. 2018), catalytic hydrolysis of acid phosphatase (Chen 2003), release of organic acids (Wu et al. 2017), and reduction of leaf net photosynthetic rate, transpiration rate, and stomatal conductance (Lim et al. 2003). It is of interest to determine whether the morphological and physiological changes occur in roots after the VOCs receive the signal molecules indicating the conditions.

Furthermore, VOCs released from the roots into the soil change the physical and chemical properties of the soil and affect the growth of adjacent plants (Achard et al. 2003). Plant roots can identify related species according to their VOC profile (Depuydt 2014). For example, ethylene, a wellknown phytohormone, is a critical component of the VOCs and can mediate the growth and $\mathrm{P}$ remobilization in the root systems by the expression of the $P$ deficiency-responsive gene under low-P stress conditions (Nagarajan \& Smith 2012, Zhu et al. 2016). The results of the present study show that under $P$ deficiency stress, the root VOCs of Chinese fir influenced the accumulation of $\mathrm{P}$ and root morphology and 
were to some extent correlated. However, further research is needed to determine the other specific VOCs that promote physiological changes (Wu et al. 2017).

\section{Conclusions}

Under different $\mathrm{P}$ supply conditions, the type and quantity of root VOCs were significantly different in two Chinese fir families. Under total $P$ deficiency, the amount of VOCs of family No. 25 and 32 was lower that than under $\mathrm{P}_{1}$ treatment. Low $\mathrm{P}$ supply significantly promoted growth of both average root diameter and root volume in family No. 25 seedlings compared with family No. 32 seedlings. For family No. 25, the increment of root volume was negatively correlated with 18 individual types or total amounts of VOCs. For family No. 32 seedlings, there was a negative correlation between 17 individual VOCs and the increment of root average diameter. Under $P$ deficient treatment, the $P$ accumulation of the whole plant and aboveground $\mathrm{P}$ distribution of family No. 25 and 32 seedlings were significantly lower than that of $P$ supplied treatment. The types and amounts of 18 VOCs were positively correlated with accumulation of $P$, aboveground $P$ distribution, and belowground $\mathrm{P}$ distribution, but the opposite pattern was observed for the $\mathrm{Pr} / \mathrm{Ps}$ ratio in family No. 25 seedlings.

\section{Acknowledgments}

This research was financially supported by the National Natural Science Foundation of China (Grants no. U1405211, 31370531) and the Science and Technology Plan Project of Fuzhou City, China (2017-N-35). We would like to thank Professor Zhigang $\mathrm{Yi}$ and Xingran Huang and Wei Lin for help with our chemical analyses, Minghui Yang and Yuan Yang for help with the experiment, and Mulualem Tigabu for reviewing the article.

\section{References}

Achard P, Vriezen WH, Van Der Straeten D, Harberd NP (2003). Ethylene regulates Arabidopsis development via the modulation of DELLA protein growth repressor function. Plant and Cell 15: 2816-2825. - doi: 10.1105/tpc.015685

Asensio D, Penuelas J, Filella I, Llusia J (2007). On-line screening of soil VOCs exchange responses to moisture, temperature and root presence. Plant and Soil 291: 249-261. - doi: 10.1007/s11104-006-9190-4

Bruinsma M, Posthumus MA, Mumm R, Mueller MJ, Van Loon JJA, Dicke M (2009). Jasmonic acid-induced volatiles of Brassica oleracea attract parasitoids: effects of time and dose, and comparison with induction by herbivores. Journal of Experimental Botany 60: 2575-2587. - doi: 10.1093/jxb/erp101

Burton AL, Lynch JP, Brown KM (2013). Spatial distribution and phenotypic variation in root cortical aerenchyma of maize (Zea mays L). Plant and Soil 367: 263-274. - doi: 10.1007/s11104012-1453-7

Chen $\mathrm{H}$ (2003). Phosphatase activity and P fractions in soils of an 18-year old Chinese fir (Cun- ninghamia lanceolata) plantation. Forest Ecology and Management 178: 301-310. - doi: 10.1016 /S0378-1127(02)00478-4

Chen ZY, Li Q, Zou XH, Ma XQ, Wu PF (2016). Effect of neighboring competition on photosynthetic characteristics and biomass allocation of Chinese fir seedlings under low phosphorus stress. Chinese Journal of Plant Ecology 40 (2): 177-186. - doi: 10.17521/cjpe.2015.0182

Chiou TJ, Lin SI (2011). Signaling network in sensing phosphate availability in plants. Annual Review of Plant Biology 62: 185-206. - doi: 10.1146/ annurev-arplant-042110-103849

Dam NM, Qiu BL, Hordijk Vet CA LEM, Jansen JJ (2010). Identification of biologically relevant compounds in aboveground and belowground induced volatile blends. Journal of Chemical Ecology 36: 1006-1016. - doi: 10.1007/s10886-01 0-9844-9

Depuydt S (2014). Arguments for and against self and non-self root recognition in plants. Frontiers in Plant Science 5: 1-7. - doi: 10.3389/ fpls.2014.00614

Dudareva N, Negre F, Nagegowda DA, Orlova I (2006). Plant volatiles: recent advances and future perspectives. Critical Reviews in Plant Sciences 25: 417-440. - doi: 10.1080/073526806008 99973

Ens EJ, Bremner JB, French K, Korth J (2009). Identification of volatile compounds released by roots of an invasive plant, bitoubush (Chrysanthemoides monilifera spp. rotundata), and their inhibition of native seedling growth. Biological Invasions 11: 275-287. - doi: 10.1007/s105 30-008-9232-3

Falik O, Hoffmann I, Novoplansky A (2014). Say it with flowers: flowering acceleration by root communication. Plant Signal and Behavior 9 (3): e28258. - doi: 10.4161/psb.28258

Fan MS, Zhu JM, Richards C, Brown KM, Lynch JP (2003). Physiological roles for aerenchyma in phosphorus-stressed roots. Functional Plant Biology 30: 493-506. - doi: 10.1071/FP03046

Fares S, Brilli F, Noguès I, Velikova V, Tsonev T, Dagli S, Loreto F (2008). Isoprene emission and primary metabolism in Phragmites australis grown under different phosphorus levels. Plant Biology 10 (1): 38-43. - doi: 10.1055/s-2007-9654 29

Farooq TH, Tigabu M, Ma XQ, Zou XH, Liu AQ, Odén PC, Wu PF (2018). Nutrient uptake, allocation and biochemical changes in two Chinese fir cuttings under heterogeneous phosphorus supply. iForest - Biogeosciences and Forestry 11: 411-417. - doi: 10.3832/ifor2657-011

Frost CJ, Mescher MC, Dervinis C, Davis JM, Carlson JE, De Moraes CM (2008). Priming defense genes and metabolites in hybrid poplar by the green leaf volatile cis-3-hexenyl acetate. New Phytologist 180: 722-734. - doi: 10.1111/j.1469-81 37.2008.02599.x

He Y, Liao H, Yan XL (2003). Localized supply of phosphorus induces root morphological and architectural changes of rice in split and stratified soil cultures. Plant and Soil 248: 247-256. - doi: 10.1023/A:1022351203545

Lim JH, Chung IM, Ryu SS, Yun SJ (2003). Differential responses of rice acid phosphatase activities and isoforms to phosphorus deprivation. Journal of Biochemistry and Molecular Biology 36: 597-602. - doi: 10.5483/BMBRep.2003.36.6.
597

Lin C, Owen SM, Peñuelas J (2007). Volatile organic compounds in the roots and rhizosphere of Pinus spp. Soil Biology and Biochemistry 39: 951-960. - doi: 10.1016/j.soilbio.2006.11.007

Lynch JP (1998). The role of nutrient efficient crops in modern agriculture. Journal of Crop Production 1: 241-264. - doi: 10.1300/J144v01n 02_10

Lynch JP, Ho MD (2005). Rhizoeconomics: carbon costs of phosphorus acquisition. Plant and Soil 269: 45-56. - doi: 10.1007/s11104-004-1096-4 Lynch JP (2014). Root phenes that reduce the metabolic costs of soil exploration: opportunities for 21st century agriculture. Plant Cell and Environment 38: 1-10. - doi: 10.1111/pce.12451

Nagarajan VK, Smith AP (2012). Ethylene's role in phosphate starvation signaling: more than just a root growth regulator. Plant and Cell Physiology 53: 277-286. - doi: 10.1093/pcp/pcr186

Nielsen KL, Eshel A, Lynch JP (2001). The effect of phosphorus availability on the carbon economy of contrasting common bean (Phaseolus vulgaris L.) genotypes. Journal of Experimental Botany 52: 329-339. - doi: 10.1093/jexbot/52.35 5.329

Ormeño E, Fernandez C, Mévy J (2007). Plant coexistence alters terpene emission and content of Mediterranean species. Phytochemistry 68: 840-852. - doi: 10.1016/j.phytochem.2006.11.033 Peñuelas J, Asensio D, Tholl D (2014). Biogenic volatile emissions from the soil. Plant Cell and Environment 37: 1866-1891. - doi: 10.1111/pce.12 340

Pierik R, Ballaré CL, Dicke M (2014). Ecology of plant volatiles: Taking a plant community perspective. Plant Cell and Environment 37: 18451853. - doi: 10.1111/pce.12330

Plassard C, Dell B (2011). Phosphorus nutrition of mycorrhizal trees. Tree Physiology 30: 11291139. - doi: 10.1093/treephys/tpq063

Robert CAM, Erb M, Duployer M, Zwahlen C, Doyen GR, Turlings TCJ (2012). Herbivore-induced plant volatiles mediate host selection by a root herbivore. New Phytologist 194: 10611069. - doi: 10.1111/j.1469-8137.2012.04127.x Strock CF, Morrow LDLR, Lynch J (2018). Reduction in root secondary growth as a strategy for phosphorus acquisition. Plant Physiology 176: 691-703. - doi: 10.1104/pp.17.01583

Wu PF, Ma XQ, Tigabu M, Wang C, Liu AQ, Odén PC (2011). Root morphological plasticity and biomass production of two Chinese fir clones with high phosphorus efficiency under low phosphorus stress. Canadian Journal of Forest Research 41: 228-234. - doi: 10.1139/X10-198

Wu P, Shou HX, Xu GH, Lian XM (2013). Improvement of phosphorus efficiency in rice on basis of understanding phosphate signaling and homeostasis. Current Opinion in Plant Biology 16: 205-212. - doi: 10.1016/j.pbi.2013.03.002

Wu PF, Wang GY, Farooq TH, Li Q, Zou XH, Ma $X Q$ (2017). Low phosphorus and competition affect Chinese fir cutting growth and root organic acid content: does neighboring root activity aggravate $P$ nutrient deficiency? Journal of Soils and Sediments 17: 2775-2785. - doi: 10.1007/s11368-017-1852-8

Wu PF, Lai HY, Tigabu M, Wu WJ, Wang P, Wang GY, Ma XQ (2018). Does phosphorus deficiency induce formation of root cortical aerenchyma 
maintaining growth of Cunninghamia lanceolata? Trees 215 (11): 76. - doi: 10.1007/s00468018-1739-3

Zhu XF, Zhu CQ, Zhao XS, Zheng SJ, Shen RF (2016). Ethylene is involved in root phosphorus remobilization in rice (Oryza sativa) by regulat ing cell-wall pectin and enhancing phosphate translocation to shoots. Annals of Botany 118: 645-653. - doi: 10.1093/aob/mcw044

Zou XH, Wu PF, Chen NL, Wang P, Ma XQ (2015). Chinese fir root response to spatial and temporal heterogeneity of phosphorus availability in the soil. Canadian Journal of Forest Research
45: 402-410. - doi: 10.1139/cjfr-2014-03

Zou XH, Wei D, Wu PF, Zhang Y, Hu YN, Chen ST, Ma XQ (2018). Strategies of organic acid production and exudation in response to lowphosphorus stress in Chinese fir genotypes differing in phosphorus-use efficiencies. Trees 32: 897-912. - doi: 10.1007/s00468-018-1683-2

\section{Supplementary Material}

Fig. S1 - The amount of volatile organic compounds (VOCs) released from Chinese fir roots under low-phosphorus stress for 7 days.

Fig. S2 - The amount of volatile organic compounds (VOCs) released from Chinese fir roots under low-phosphorus stress for 14 days.

Link: Lai_2797@supploo1.pdf 